\title{
LÍMITES Y POSIBILIDADES DEL ANARQUISMO. PROPUESTA DE UN ANARQUISMO FOCALIZADO
}

\author{
LIMITS AND POSSIBILITIES OF ANARCHISM. PROPOSING A "FOCUSED \\ ANARCHISM"
}

\begin{abstract}
Juan Carlos Riofrio Martinez-Villalba
Ph.D. por la Pontificia Università della Santa Croce (Roma, Italia). Profesor de la Universidad de Los Hemisferios (Quito, Ecuador), titular de las cátedras de Derecho constitucional y Teoría fundamental del derecho.
\end{abstract}

\author{
Ricardo López \\ Abogado. Asesor legislativo
}

\begin{abstract}
Resumo
O objetivo deste estudo é definir as possibilidades, limites e escopo do anarquismo. É realizado um estudo qualitativo dos autores, que analisa sistematicamente as possibilidades do anarquismo. $O$ capítulo I explica quando o anarquismo foi considerado uma forma de governo na história; Observa-se que nem todos os anarquistas concordam com a idéia de um "autogoverno" absoluto, pois vários deles preferem outro tipo de governo (associações, sindicatos, cooperativas, federação etc.). Também é analisado lá qual poderia ser a melhor forma de governo. O capítulo II define os limites do anarquismo. As principais perguntas são: o anarquismo absoluto é possível? Alguma sociedade poderia faltar a todo o governo? Que tipos de limites a anarquia poderia ter? Consideraremos vários limites possíveis, como limites políticos, econômicos e legais; limites no campo militar, nas políticas públicas, nas estradas e nos serviços públicos. Então, projetamos uma maneira de incluir o anarquismo no sistema jurídico. Depois de concluir que o anarquismo absoluto não é possível, consideramos que nível de anarquismo é possível adotar e em quais campos é possível implementá-lo. A principal conclusão é que a anarquia como modo de vida não pode ser um valor absoluto e que a anarquia como forma de governo deve ser revista, se desejar obter a aprovação da sociedade. Uma certa dose de anarquismo focado poderia se adequar a qualquer país do mundo.
\end{abstract}

Palavras-chave: Anarquismo. Autogoverno. Formas de governo. Limites da direita. Princípio da subsidiariedade.

\section{Resumen}


El objetivo de este estudio es delimitar las posibilidades, los límites y el alcance del anarquismo. Se hace un estudio cualitativo de los autores, que pasa revista sistemática de las posibilidades del anarquismo. El Capítulo I explica cuándo el anarquismo ha sido considerado como una forma de gobierno en la historia; se ve que no todos los anarquistas están de acuerdo con la idea de un absoluto "auto-gobierno", pues varios de ellos prefieren otro tipo de gobierno (asociaciones, sindicatos, cooperativas, federación, etc.). También se analiza ahí cuál podría ser la mejor forma de gobierno. El Capítulo II define los límites del anarquismo. Las preguntas principales son: ¿es posible el anarquismo absoluto? ¿Podría alguna sociedad carecer de todo gobierno? ¿Qué tipos de límites podría tener la anarquía? Consideraremos varios límites posibles, como los límites políticos, económicos y legales; límites en el campo militar, en las políticas públicas, en las carreteras y los servicios públicos. Luego diseñamos una forma de incluir el anarquismo en el sistema jurídico. Después, de concluir que el anarquismo absoluto no es posible, consideramos qué nivel de anarquismo es posible adoptar y en qué campos resulta factible implantarlo. La conclusión principal es que la anarquía como forma de vida no puede ser un valor absoluto y que la anarquía como forma de gobierno debe revisarse si desea obtener la aprobación de la sociedad. Una cierta dosis de anarquismo focalizado podría convenir a cualquier país del mundo.

Palabras clave: Anarquismo. Autogobierno. Formas de gobierno. Límites del derecho. Principio de subsidiariedad.

\begin{abstract}
The aim of this study is to delimitate the possibilities, limits and scope of anarchism. A qualitative study of the authors is made, which systematically reviews of each possibility of anarchism. Chapter I is focused on the notion of anarchism in history as a form of government; we find that not all anarchists agree with the idea of an absolute "self-government"; they are thinking in other types of government (associations, syndicates, cooperatives, federation, etc.). There we will also analyze which could be the best form of government. Chapter II defines the limits of anarchism. The main questions here are: Is absolute anarchism possible? Could any society be absolutely ungoverned? What kind of limits could anarchy have? We will consider many possible limits, such as political, economic, and legal limits; in the army, in political policy, in roads and public services. Then we design a way to include anarchism in the legal system. After concluding that absolute anarchism is not possible, we consider what level of anarchism can be adopted and in which fields it is possible. The main conclusion is that anarchy as a way of living cannot be an absolute value, and anarchy as a form of government must be revised, if it hopes to gain some approval of society. It may be convenient for each country some level of a focused anarchism.
\end{abstract}

Keywords: Anarchism. Self-government. Forms of Government. Limits of the Law. Subsidiarity Principle.

\title{
CONSIDERACIONES INICIALES
}


En este documento procuramos delimitar las posibilidades, los límites y el alcance que en la realidad el anarquismo puede tener. Estudiaremos varios casos, en donde revisaremos si es posible una anarquía absoluta, o si resulta necesario al menos un cierto nivel de autogobierno. Estudiaremos esto en los siguientes capítulos:

1. El anarquismo como forma de gobierno, en general.

2. Los límites prácticos del anarquismo.

3. Las posibilidades reales del anarquismo.

Con estos antecedentes, luego propondremos algunos criterios para descubrir donde es posible —en incluso exigible— la anarquía.

\title{
II. ANARQUISMO COMO FORMA DE GOBIERNO
}

\section{II.1. Gobierno vs. no gobierno}

¿Puede la anarquía ser considerada como una forma de gobierno? La mayoría de los pensadores clásicos y modernos parecen rechazar esta idea. De hecho, Heródoto (2013), Aristóteles (1999), Platón (1892), Tomás de Aquino (2001), Maquiavelo (1998) y Loewenstein (1969), entre otros, nunca incluyen la anarquía en sus propias clasificaciones de las formas de gobierno. Solo un reducido número de pensadores políticos consideran el anarquismo como una forma de gobierno. Un ejemplo singular de alguien que acepta la anarquía como una forma de gobierno es Hobbes (1642), quien en De cive (VII, 2) identifica de manera llana la democracia y la anarquía, manifestando que la única distinción entre ellas serían los sentimientos de las personas.

Con frecuencia se contraponen anarquismo y gobierno. De esta manera, Bakunin (1871) desarrollaba su idea de anarquismo:

\begin{abstract}
En una palabra, nosotros rechazamos toda legislación —privilegiada, autorizada, oficial y legal - y toda autoridad e influencia, aunque puedan provenir del sufragio universal, ya que estamos convencidos de que ello solo puede beneficiar a una minoría dominante de explotadores, lo que va en contra de los intereses de la gran mayoría en sujeción a ellos. En este sentido, somos realmente anarquistas (la traducción es nuestra).
\end{abstract}

Según esta forma de pensamiento, la anarquía es radicalmente antitética con el concepto de gobierno. No tiene nada que ver con el gobierno. Jamás podría hablarse de la anarquía como una "forma de gobierno". Repárese que quienes 
piensan así solo tienen en mente un gobierno donde "alguien gobierna a otros", y no consideran la posibilidad del "auto-gobierno". Si el autogobierno es posible - y lo esla anarquía debe considerarse una "forma de gobierno".

\section{II.2. Problemas para entender el anarquismo como auto-gobierno}

Las personas no siempre son coherentes con sus propias ideas. Eso resulta frecuente entre los simpatizantes del anarquismo. Odian al gobierno estatal, pero la mayoría de las veces lo reemplazan con otro tipo de gobierno: con un gobierno federal, como el propuesto por Proudhon (1923); gobiernos asociacionistas (Kropotkin 1892), gobiernos cooperativistas (Bakunin 1990 y Woodcock 1977); autoridades sindicales sobre el movimiento anarcosindicalismo (Rojava), etc. Algunos argumentan que los gobiernos de las asociaciones son diferentes, porque son temporales, mientras el gobierno estatal es permanente; la realidad es que en ambos casos nos encontramos con autoridades que suelen durar unos pocos años. Para nosotros los mencionados gobiernos son realmente una "forma de gobierno", pero no necesariamente de "autogobierno".

Existen pocos anarquistas absolutos. Entre ellos están William Godwin (1793), Max Stiner (1844) y Josiah Warren (1841), quienes se mueven dentro de un anarquismo individualista. Ellos condenan cualquier forma de gobierno y piensan que debe evitarse: tanto un gobierno asociacionista, como uno sindicalista, cooperativista o federalista. Las obras de estos autores suelen carecer de una teoría bien desarrollada acerca la organización humana en "sociedad" —si fuera posible—, y de una propuesta aceptable de resolución de conflictos que surjan entre los ciudadanos.

Muchas personas hoy podrían simpatizar con la idea de, algo así como, un "anarquismo focalizado" que no necesariamente involucre todas las áreas del gobierno. Hay quienes piensan que el estado no debería meterse en algunos temas importantes como el feminismo, el mercado, el amor libre o la educación. Emma Goldman (1910) y Voltairine de Cleyre (1901) fueron anarquistas que lucharon por empoderar a las mujeres de la clase trabajadora de España para liberarlas de las estructuras patriarcales y de la autoridad machista. El anarco-capitalismo rechaza cualquier tipo de intervención del Estado en el mercado, aunque no necesariamente 
en otras áreas ${ }^{1}$. Émile Armand (1929), John Henry Mackay (1891) y Michel Onfray (2000), entre otros, han propuesto una especie de anarquismo en el amor, que propone que el Estado debe permitir el poliamor, la bisexualidad, la homosexualidad y otros comportamientos sexuales. Finalmente, también podemos encontrar anarquistas en la educación como William Godwin (1793) y Francesc Ferrer (1908), quienes entienden la educación estatal como una tenaza del gobierno para replicar los privilegios de la clase dominante.

\section{II.3. La mejor forma de Gobierno}

Una pregunta clásica en política es cuál debe considerarse la mejor forma de gobierno. A lo largo de la historia muchos han intentado responderla. Hasta la Edad media, la mayoría de los pensadores estaban de acuerdo que la monarquía era la mejor forma de gobierno. No fue sino hasta la Era moderna que este pensamiento comenzó a cambiar, y hoy en día encontramos un fuerte consenso sobre la democracia.

Tomás de Aquino (2015) tiene una idea muy original en este tema. Como la mayoría de los autores de su tiempo, él también favoreció la monarquía. Según él, el gobierno de uno es mejor que el gobierno de muchos porque proporciona más paz, seguridad, leyes menos contradictorias, más unidad en la sociedad y porque un mayor poder permite obtener mayores beneficios. Aun así, observa que las demás formas de gobierno también tienen sus propios beneficios. Aquino no fue un autor simplista, y por eso agrega:

Para la buena constitución del poder supremo en una ciudad o nación es preciso mirar a dos cosas: la primera, que todos tengan alguna parte en el ejercicio del poder, pues por ahí se logra mejor la paz del pueblo, y que todos amen esa constitución y la guarden. La segunda mira a la especie de régimen y a la forma constitucional del poder supremo. De la cual enumera el Filósofo, varias especies; pero las principales son la monarquía, en la cual es uno el depositario del poder, y la aristocracia, en la que son algunos pocos. La mejor constitución en una ciudad o nación es aquella en que uno es el depositario del poder y tiene la presidencia sobre todos, de tal suerte que algunos participen de ese poder $y$, sin embargo, ese poder sea de todos, en cuanto que todos pueden ser elegidos y todos toman parte en la elección. Tal es la buena constitución política, en la que se juntan la monarquía - por cuanto es uno el que preside a toda la nación-, la aristocracia

\footnotetext{
${ }^{1}$ Anotamos que muchos anarquistas creen que el anarco-capitalismo no puede considerarse parte del movimiento anarquista, debido al hecho que el anarquismo ha sido históricamente un movimiento anticapitalista.
} 
- porque son muchos los que participan en el ejercicio del poder- y la democracia, que es el poder del pueblo, por cuanto estos que ejercen el poder pueden ser elegidos del pueblo y es el pueblo quien los elige.

Tal fue la constitución establecida por la ley divina, pues Moisés y sus sucesores gobernaban al pueblo, gozando de un poder singular, lo que equivalía a una especie de monarquía. Después eran elegidos setenta y dos ancianos para ejercer el poder, pues se dice en el Dt 1,15: Tomé de vuestras tribus varones sabios y nobles y los constituí por príncipes; y esto era una aristocracia. $Y$ a la democracia pertenecía el que eran elegidos de entre todo el pueblo, pues se dice en Ex 18,21: Escoge de toda la multitud varones sabios, etc., y eran elegidos por el pueblo, según Dt 1,13: Dadme de entre vosotros varones sabios, etc. De manera que era la mejor constitución política establecida por la ley (Summa Th. I-II, q. 105, art. 1).

Aunque el Aquinate claramente favorece la monarquía, en este pasaje concilia su propuesta con todas las formas de gobierno conocidas hasta el momento. Quizás el único problema que tiene es que, influenciado por Aristóteles, solo considera tres formas de gobierno, y no todas. Habla de una forma mixta de gobierno que es "parcialmente reino", "parcialmente aristocracia" y "parcialmente democracia". Sin inconveniente alguno podríamos agregar que la mejor forma de gobierno también debe ser "parcialmente anarquista".

De hecho, vivimos en una era en la que la mayoría de los países no se adhieren a un estilo de gobierno único, sino que prefieren una forma mixta. Pensemos en el típico régimen presidencialista. De alguna manera, la monarquía resuena en el presidente: aún con poderes algo restringidos, puede tomar decisiones importantes sin la aprobación de otras instancias (especialmente en Estado de emergencia, problemas económicos u otros temas específicos). La aristocracia, donde los virtuosos son elegidos por sus capacidades en un campo específico, podría estar representada por el Gabinete y sus ministros, elegidos por el Presidente en consideración de sus virtudes. Finalmente, la democracia aparece de manera clara en el Legislativo, con sus diputados elegidos por la sociedad. Además, cabe recordar otros mecanismos de democracia directa, como los referéndums, propuestas populares de proyectos de ley, la "silla vacía", etc. En todos estos casos, se adoptan decisiones a través de la suma de voluntades.

Vemos que en esta combinación de formas de gobierno, también es necesario abrir espacios donde el gobierno no pueda intervenir, ni tomar decisiones: espacios de libertad para los individuos, de autorregulación para las sociedades menores. Aquí es donde la anarquía encuentra su justo lugar y donde puede ser exigible: pensemos en espacios como los de la familia, el ocio y la educación donde debe imperar la 
libertad humana.

La anarquía pura es muy problemática en las grandes sociedades. Probablemente, en ellas solo podemos introducir un anarquismo parcial, centrado en algunos asuntos, mezclado con algunas otras formas de gobierno. En los próximos capítulos, consideraremos los límites específicos y las posibilidades anarquistas, para definir qué podría ser un anarquismo real y dónde éste se convierte en una utopía.

\section{LÍMITES DEL ANARQUISMO}

En el presente apartado abordaremos cuáles son los límites del anarquismo, es decir, dónde el anarquismo simplemente se vuelve imposible. Resumimos estos límites en cuatro principales:

\section{III.1. Seguridad militar}

Los anarquistas que propugnan la desaparición del Estado, consideran que el poder militar solo sirve para oprimir a las clases explotadas $y$, para que las clases privilegiadas sigan posicionadas en el poder. Pero si se considera la seguridad territorial de un estado (guerras, invasiones, etc.) y a la seguridad interna de sus habitantes, el análisis cambia radicalmente.

Remontémonos al feudalismo: dentro de una comunidad productiva, existía la necesidad de que alguien -el señor feudal-garantice la seguridad de los pobladores, y para ello debía tener un cierto poderío que evite las incursiones armadas externas. Posteriormente, aparecieron los comerciantes que transferían los productos como intermediarios, los burgueses cuya actividad requirió también de seguridad, y todo esto dio como resultado la formación del Estado. La creación del Estado se da por la necesidad de que exista una unificación territorial que garantice la seguridad de todos. Los ataques armados solo se pueden repeler mediante las armas. Históricamente, las comunidades siempre han tenido la necesidad de protegerse con armas de las amenazas externas; quizás esto es instintivo, así como los animales marcan su territorio. Por ello, es interesante partir desde este punto para demostrar cómo la necesidad de tener una seguridad militar es uno de los límites del Anarquismo.

Según Cappelletti (2010, p.37), el anarquismo repudia las guerras entre 
Estados, ante todo porque repudia al Estado. Toda guerra de este tipo, en efecto, tiene objetivo afirmar y expandir el poder de un Estado en detrimento de otro. De forma yuxtapuesta Verdugo (2002, p.54) dice que a partir del siglo XIX, todo Estado cuenta con un grupo armado cuya función es velar por la paz y defensa externa de éste.

En filosofía política siempre ha sido razonable repudiar la guerra, defenderse de forma armada contra la guerra iniciada por otro. Quien sufre un ataque necesita una defensa militar organizada para repelerlo. Un país militarmente anárquico es un país monumentalmente imprudente que deja a sus ciudadanos en la inseguridad. Una sociedad sin Estado, ni gobierno, donde sólo hay autogestión de la comunidad y de los individuos anárquicos, no puede enfrentar las grandes guerras.

\title{
III.2. Necesidad de leyes
}

Es indispensable que las sociedades que han adquirido proporciones mayores tengan a alguien que ponga reglas mínimas de comportamiento: que defina si se circula por la derecha o por la izquierda, que diga qué moneda se usará, cuáles son las normas de evicción en la compraventa, que establezca la forma de los pagarés, letras de cambio, etc. En una sociedad absolutamente anarquista no existe seguridad jurídica, ni paz.

Hobbes, en su célebre obra El Leviatán, hace hincapié en la necesidad que de establecer y cumplir las leyes:

\begin{abstract}
Ley de naturaleza, (lex naturalis) es un precepto o norma general, establecida por la razón, en virtud de la cual se prohíbe a un hombre hacer lo que puede destruir su vida o privarle de los medios de conservarla; o bien, omitir aquello mediante lo cual piensa que pueda quedar su vida mejor preservada. Aunque quienes se ocupan de estas cuestiones acostumbran a confundir Jus y Lex, Derecho y Ley, precisa distinguir esos términos, porque el Derecho consiste en la libertad de hacer o de omitir, mientras que la LEY determina y obliga a una de esas dos cosas. Así, la Ley y el Derecho difieren tanto como en Obligación como en Libertad, que son incompatibles cuando se refieren a una misma materia (Hobbes, 1980, p.101)
\end{abstract}

Hobbes añadía que, justamente por la condición del hombre en estado de naturaleza (que "es una condición de guerra de todos contra todos, en la cual cada uno está gobernado por su propia razón"), resulta necesario establecer la primera regla general: la búsqueda de la paz.

Desde otro punto, Rousseau también ve que el hombre debe superar su estado natural para sobrevivir: 


\begin{abstract}
Supongo que los hombres han llegado al punto en que los obstáculos en el camino de su preservación en el estado de naturaleza muestran que su poder de resistencia es mayor que los recursos a disposición de cada individuo para su mantenimiento en ese estado. Esa condición primitiva ya no puede subsistir; y la raza humana perecería a menos que cambiara su forma de existencia (El Contrato Social, 1762; 2003, p.46).
\end{abstract}

Por estas razones propone su contrato social, que sería:

[...] una forma de asociación que defienda y proteja con la fuerza común la persona y los bienes de cada asociado, y por la cual cada uno, uniéndose a todos, no obedezca sino a sí mismo y permanezca tan libre como antes. Este es un problema fundamental cuya solución da el Contrato Social (ROUSSEAU, 2003, p. 14).

Aunque ambos autores guardan notables diferencias, los dos entienden que el ser humano para ser libre y poder conservarse, necesita tener leyes que lo protejan; necesita definir unos límites para poder coexistir en un cuerpo colectivo. Respecto a nuestro tema, concluimos que es imposible que una sociedad viva sin un mínimo de normas y estructura. Una sociedad no puede ser tan anárquica que carezca absolutamente de ellas.

Las leyes son necesarias para que el trajín ordinario de las sociedades no decaiga en el caos. Un mínimo de orden resulta necesario. Sin embargo, aquí destacamos una variable: el tamaño de las comunidades. En las comunidades pequeñas, donde no existe un gran número de habitantes, no es absolutamente necesario emitir leyes que fijen estas regulaciones, pues basta con las instituciones informales que existen y que regulan la conducta de sus miembros. Así pasa, por ejemplo, en el Ecuador con ciertos pueblos nómadas "no contactados".

En cambio, contar con leyes es algo indispensable en las poblaciones más numerosas, donde ciertos sectores (v.gr. económico, comercial, vial, criminal, etc.) no pueden subsistir una hora sin ellas. Sin ellas no habría ni moneda, ni contratos regulados en temas complejos, ni seguridad sobre varias cuestiones del cobro, ni conciencia de que ciertos delitos no se deben cometer, entre otras cosas. Las leyes no lo son todo, pero proporcionan una cierta dosis de tranquilidad. Y quien tiene leyes, tiene autoridades que las imponen.

\title{
III.3. Control de los delitos
}

Respecto a los delitos y las penas Cappelletti afirma: 
Si consultamos las estadísticas nos será fácil comprobar que una gran mayoría de los delitos en cualquier lugar del mundo está constituida por los delitos contra la propiedad, ahora bien una sociedad que haya eliminado la propiedad privada, como la sociedad anarquista sin duda alguna, no dará ocasión para esta clase de acciones delictivas. Quedan, sin embargo, los delitos contra las personas, que son comúnmente los más graves. Pero, si analizamos las causas de los mismos, no tardaremos en advertir que éstas se encuentran, en la mayoría de los casos, en conflictos de intereses, los cuales suponen la existencia del dinero y de la propiedad privada. Eliminada esta, quedarían automáticamente eliminados estos crímenes contra las personas (2010, pp. 41-42).

El autor entiende la propiedad privada como un factor que incentiva la actividad criminal. Parte de un enfoque comunista donde se imputan todos los problemas de la sociedad a la propiedad privada. Si esto fuera cierto, los regímenes comunistas no hubieran conocido el crimen, cosa que se puede negar revisando los crímenes acaecidos en la Unión Soviética (que frecuentemente castigaba con pena de muerte). Allí era crimen pensar distinto.

Si al Estado se le impide el manejo del proceso penal, entonces los privados deberían encargarse del asunto criminal. Según Robert Nozick (1974), un independiente podría ser excluido del uso de la justicia privada porque se sabe que su proceso conlleva mucho riesgo y peligro, es decir, tiene un mayor riesgo (en comparación con algún otro procedimiento) de castigar a una persona inocente o de ir demasiado lejos en castigar a una persona culpable, o en virtud de no saber que el procedimiento no es arriesgado.

Por lo expuesto, hemos de afirmar que cuando las conductas delictivas atentan contra la integridad de los ciudadanos, resulta necesario establecer autoridades y procesos legales que manejen el conflicto de los antisociales, para poder evitar aquello que afirmaba Herbert Hart (1998), que la sociedad se convierta en un "club de suicidas". El derecho penal exige autoridades previas, leyes previas y claras, delitos tipificados, un proceso justo y unas penas preestablecidas. Sin esto, la sociedad se convierte en un foco de violencia. El anarquismo en el derecho penal no es saludable.

\section{III.4. Distribución de recursos y obras públicas}

Sobre la distribución de los recursos se han formado diversas corrientes anarquistas. En primer lugar, Cappelletti (2010) señala que el sistema anárquico proponía el mutualismo proudhoniano, el mismo que se basaba en la asociación de productores y consumidores, y en el trueque. Bakunin, que también se enlista entre los anarquistas, proponía la siguiente fórmula: la tierra y los instrumentos de 
producción deben ser comunes, pero el fruto del trabajo debe ser repartido en proporción de esfuerzo y la calidad del trabajo de cada uno. Surgió finalmente una tercera corriente, los anarco-comunistas, con Kropotkin a la cabeza, quien propuso suprimir por completo cualquier forma de salario. No sólo la tierra y los medios de producción deben ser comunes, según ellos, sino también el producto. El criterio de distribución está dado por las necesidades reales de cada miembro de la sociedad.

Estos tres sistemas sociales presentaron objeciones, nunca resultas de manera completa y satisfactoriamente (cfr Cappelletti, 2010). Tales teorías nunca pudieron resolver el manejo de los recursos, ni ayudaron en la instauración y desarrollo del anarquismo. El mismo Kropotkin se cuestionó qué pasaría con los que no cumplan sus pactos, con los que no quieran trabajar, con los que decidan quebrantar las leyes o las costumbres no escritas. "El anarquismo quizás sea bueno para una humanidad superior, pero no para los hombres de estos tiempos" (cfr. GÓMEZ-MÜLLER, 2014, p. 104).

Ciertas cosas simplemente no pueden estar en manos de todos, a discreción de cada uno: las instituciones financieras, la moneda de una sociedad, el sistema vial de una ciudad, o las carreteras interprovinciales, el sistema de trenes, la señalización en el tránsito, la distribución del espectro radioeléctico, la planificación e implantación del alcantarillado, el servicio de agua potable, la dotación de energía eléctrica, etc. El trazado de calles, alcantarillado, cables de energía eléctrica no pueden quedar al capricho de cada ciudadano; bastarían unos pocos que se opongan, para encarecer notablemente estos servicios, o para tornarlos imposibles.

En conclusión, es impensable un anarquismo absoluto en las grandes sociedades. Además, siempre muestra los cuatro límites antes señalados.

\section{POSIBILIDADES REALES DEL ANARQUISMO}

Según lo visto en el anterior apartado, el anarquismo absoluto (sin ninguna autoridad) es simplemente inviable en las grandes comunidades. En teoría, solo es factible montarlo en pequeños asentamientos humanos: mientras más pequeños, más posible. De hecho, los grupos anarquistas diseminados en el mundo suelen ser grupos reducidos. Veamos unos cuantos casos para ver cómo funcionan.

En la historia varias comunidades han logrado desvincularse, en menor o mayor medida, del poder estatal y gozar de un auto-gobierno relativamente amplio. Algunos 
anarquistas citan casos como el de Barbacha, una región con 34 millas desde el Norte de Algeria, con una población indígena Amazigh de escasos recursos, de pocas calles y casas; después de las revueltas del año 2001, bajo el eslogan "Ustedes no nos pueden matar, iya estamos muertos!", lograron expeler la fuerza policial y el influjo de las autoridades democráticas de la zona. En el acto crearon una forma de autogobierno que recogía la basura, distribuía el petróleo, mantenía las escuelas y la limpieza pública. Relativamente cerca está Rojava, la Autónoma Administración del Norte y Este de Syria (NES), que de facto es una región autónoma, donde existen algunos movimientos anarquistas que tienden hacia unas "libertarian transnational aspirations" (GLIOTI, 2006), aunque en la región subsisten varias estructuras tribales, capitalistas y patriarcales. Otro ejemplo, que suele traerse a colación es Fejuve (la Federación de Juntas Vecinales de El Alto), una comunidad de unos 600 vecinos creada en La Paz (Bolivia) en 1957 como gobierno paralelo al municipal, organizada para la provisión de servicios públicos, la construcción de edificios y la mejora del empleo (GELDERLOOS, 2010).

La Fejuve ha bloqueado algunos proyectos gubernamentales de privatización del gas natural y las reservas de agua, ha introducido tasas y ha llegado a crear una universidad pública (GLIOTI, 2016). Varias comunidades indígenas de México han tenido sus éxitos relativos ${ }^{2}$, donde lograron elegir a sus autoridades municipales $\sin$ intervención de los partidos políticos, mediante sus "usos y costumbres", es decir, mediante asambleas comunitarias. Un caso emblemático es el Consejo Indígena Popular de Oaxaca "Ricardo Flores Magón", nombre inspirado en el anarco-comunista mexicano de principios del siglo 20 , sobre cuya herencia y principios la organización se basa en las decisiones tomadas a través de asambleas (ESCOBEDO CETINA, 2000).

En los casos anteriores no estamos, pues, ante un anarquismo absoluto, sino —en el mejor de los casos_- ante un anarquismo muy parcial, donde las comunidades cambian unas autoridades (las estatales) por otras más cercanas. El auto-gobierno personal nunca se da. Hemos de recalcar, además, que muy rara vez estas comunidades dejan de usar todos los beneficios que el poder estatal les otorga directa

\footnotetext{
${ }^{2}$ El caso fue llevado a la Suprema Corte de Justicia de la Nación (SCJN), que el 2011, en una controversia constitucional, permitió a Cherán regirse por usos y costumbres. Posterior a las elecciones comunitarias, una sentencia del Tribunal Electoral del Poder Judicial de la Federación (TEPJF), aprobó el nuevo gobierno, en la medida en que sea un proyecto del que la comunidad se haga responsable e impulse la seguridad, la justicia y la democracia.
} 
o indirectamente: carreteras con regiones vecinas, agua, luz eléctrica, comunicaciones, etc. Los hechos históricos más bien demuestran que cuando el Estado no puede proporcionar algún servicio, las comunidades se las arreglan para obtenerlos.

Tomando en cuenta esto, analizaremos ahora las posibilidades de un anarquismo focalizado en diferentes áreas que las comunidades numerosas deben manejar (no en los asentamientos menores). En realidad se podrían escribir $-\mathrm{y}$ se ha escrito- mucho sobre cada uno de estos tópicos, pero para efectos de este estudio nos basta hacer una breve referencia. Solo intentamos aquí mostrar el panorama por dónde el anarquismo podría desarrollarse. Otra cosa excedería nuestras posibilidades de espacio que tenemos en este artículo.

\section{IV.1. Derechos familiares y parentales}

Tradicionalmente el Estado ha regulado varios temas de la familia: el contrato de matrimonio (su forma de celebrarse, inhabilidades, etc.), la separación conyugal, el divorcio, los bienes patrimoniales de sus miembros y todo lo que ello conlleva (herencias, patrimonio del menor, etc.), además de proteger la vida y seguridad de sus integrantes. Sin embargo, respetaba una amplia patria potestad que tenían los padres sobre sus hijos, especialmente en temas sensibles como el credo religioso, la educación que ellos desean dar a sus hijos, la forma de criarlos, las sanciones que ellos podían dar a sus hijos, el ambiente familiar, entre otras cosas. Es palpable cómo durante las últimas décadas el Estado ha comenzado a ingresar en la intimidad familiar para reemplazar a los padres en la toma de decisiones.

Las cosas se están volviendo complicadas en algunos lugares. Quizá donde peor están es en Noruega, donde los funcionarios del Barnevernet (Servicio de Bienestar Infantil) se llevan a los menores a orfanatos, porque en sus visitas ven que la casa está un poco desordenadas, o descubren que no les dan a los niños las golosinas que piden, o que se les ha pegado una palmada o zarandeado. La medida entonces que toman es la de la separación forzosa de los hijos por "falta de competencias parentales", prohibiéndoles a los padres, incluso, visitarlos en el orfanato durante años, porque supuestamente su presencia desequilibraría emocionalmente al hijo. Con todo, no han faltado denuncias contra las autoridades que claman por una mayor libertad y un mínimo intervencionismo estatal en este 
campo ${ }^{3}$.

Parece que con estos problemas, debería haber un espacio de libertad especialmente amplio para que los padres puedan criar a sus hijos de acuerdo con sus convicciones. Muchos pactos de derechos humanos consagran esta libertad, pero la práctica del gobierno en los últimos años ha socavado este tipo de libertad. Solo de manera excepcional la autoridad estatal debería poder intervenir en la vida familiar, es decir, solo cuando existan razones serias y proporcionadas. Entre otras, estas razones pueden ser las infracciones graves de la vida conyugal, la separación matrimonial, la anulación de algunos actos, la validación del matrimonio, así como cuándo es importante evitar daños verdaderos y graves a los hijos y cónyuges ${ }^{4}$.

En el fondo, lo que hoy se tiende a pasar por desapercibido es que la familia es una comunidad naturalmente soberana para tomar las decisiones que le pertenecen por naturaleza, sin coacción de ninguna persona ni autoridad. En general, ninguna autoridad, ni ninguna persona privada tienen el poder o el derecho de intervenir en el desarrollo interno de la vida conyugal o familiar ${ }^{5}$. Esta soberanía familiar es un buen justificativo para consagrar un marco focalizado de un justo anarquismo en estos temas.

\section{IV.2. Escuela y educación superior}

Es notorio cómo en los últimos años el peso de la regulación estatal de la educación ha crecido exponencialmente. Muchos profesores de colegios y universidades hoy dedican buena parte de las horas de su trabajo a redactar informes que continuamente solicitan las autoridades estatales, o a defenderse de no haber cumplido en su totalidad el reglamento impuesto por los gobernantes. Esto se debe a muchos factores: la entrada del sistema de Bolonia en la academia, el creciente influjo de las facultades de pedagogía en los currículos educativos (gracias al control de los

\footnotetext{
3 Tantos abusos de las autoridades estatales han sido denunciados por 170 expertos noruegos de diversas profesiones (psicólogos, médicos, profesores, abogados, trabajadores sociales etc.), en una carta abierta dirigida a la Ministra de Infancia, Igualdad e Inclusión, Solveig Horne. Se denuncia que "bajo las leyes y las prácticas actuales, un número desconocido de menores está sufriendo por la incompetencia y el abuso de las autoridades". Véase la carta en https://avskildabarn.se/2016/03/30/notice-of-concern-the-situation-within-norwegian-child-protectionservices/ (último acceso 2-XI-2019).

${ }^{4}$ Estos motivos pueden ser el incumplimiento grave de deberes de la vida conyugal, la separación conyugal, la nulidad, convalidación o sanación del matrimonio, así como cuando se trata de evitar el daño cierto y grave de los hijos y del cónyuge.

${ }^{5}$ En este sentido cfr. JUAN PABLO II, Carta a las familias, n. 17; HERVADA, 2000, p. 209.
} 
certificados de aptitud docente), la imposición de una lista oficial de libros de texto que conceden beneficios a unas pocas editoriales bien relacionadas con el Estado... En algunos lugares hasta se ha llegado a prohibir la educación en casa (home schooling) ${ }^{6}$.

Sobre la educación de los menores debemos reafirmar lo dicho por la Carta de los Derechos de la Familia (1983), que:

los padres tienen el derecho originario, primario e inalienable de educarlos; por esta razón ellos deben ser reconocidos como los primeros y principales educadores de sus hijos"; ellos "tienen el derecho de educar a sus hijos conforme a sus convicciones morales y religiosas, teniendo presentes las tradiciones culturales de la familia que favorecen el bien y la dignidad del hijo $(\text { art. } 5, a)^{7}$.

La Declaración Universal de los Derecho Humanos ${ }^{8}$ y muchos otros tratados también contienen la misma directriz ${ }^{9}$. Esta libertad se puede concretar en varios aspectos, como el derecho a proporcionar educación a través de los instrumentos, medios e instituciones que los padres consideren convenientes y necesarios, ya que participan directamente en el trabajo educativo e intervienen indirectamente mediante la supervisión y el control de los procesos educativos.

Por lo expresado, esta facultad de los padres de educar a sus hijos menores es un derecho-deber originario, esencial, primario, insustituible, exclusivo, inalienable, indelegable y preferente. En este caso, el Estado es simplemente incompetente de inmiscuirse para tomar la última decisión sobre la educación de los hijos menores, sobre todo en cuando se trate de cuestiones sensibles como la educación relacionada con la moral y la religión.

En la educación superior también la presión estatal ha crecido y pretende controlarlo todo. Muchas universidades privadas son tratadas como si fueran instituciones públicas, en todos los aspectos (temas financieros, elección de autoridades, obligación de ser sin fines de lucro, control del presupuesto, fijación de becas obligatorias, etc.). Un poco de anarquía, de menos gobierno estatal, y de más

\footnotetext{
${ }^{6}$ V.gr. en Ecuador, que desaparecieron con la nueva Ley Orgánica de Educación Intercultural (2011).

${ }^{7}$ En el mismo sentido, cfr. MESSNER, 1967, p. 613-615.

${ }^{8}$ DUDH, 10-XII-1948, Art. 26.3. "Los padres tendrán derecho preferente a escoger el tipo de educación que habrá de darse a sus hijos".

${ }^{9}$ Así, por ejemplo, el art. 13.2 del Pacto Internacional de Derechos Económicos, Sociales y Culturales (1966), señala que los Estados se comprometen "a respetar la libertad de los padres y, en su caso, de los tutores legales, de escoger para sus hijos o pupilos escuelas distintas de las creadas por las autoridades públicas, siempre que aquéllas satisfagan las normas mínimas que el Estado prescriba o apruebe en materia de enseñanza, y de hacer que sus hijos o pupilos reciban la educación religiosa o moral que esté de acuerdo con sus propias convicciones".
} 
gobierno corporativo o asociativo parecería bastante recomendable en este ámbito.

\section{IV.3. Conciencia, cuestiones morales y religiosas}

Sin duda, los temas de conciencia, morales y religiosos son materias sensibles en las que el Estado no puede adoctrinar a los menores sin el permiso de los padres. Ya hemos visto alguna normativa internacional en este sentido, aunque hay más ${ }^{10}$. Lamentablemente, la práctica gubernamental de los últimos años ha ido minando estas libertades.

Además, el Estado tiene el serio deber de respetar la conciencia y las creencias de las personas de todas las edades. En una gran cantidad de casos, hoy se acepta la objeción de conciencia contra los mandatos de la autoridad, pública o privada: servicio militar, periodismo, ciertas prácticas médicas, cuestiones educativas, etc. Al mismo tiempo, también han aparecido recortes serios en algunos lugares del mundo. Por ejemplo, a veces no se ha reconocido el derecho de las enfermeras para no contribuir en un aborto, el de ciertos funcionarios a no hacer ciertas inscripciones que su conciencia le prohíbe, cuando incluso puede haber otras enfermeras o funcionarios que podrían reemplazarlos sin serias molestias para la administración general. Vemos reprobable esta última imposición estatal de una doctrina. El Estado tiene el deber de reconocer la libertad de conciencia, el derecho a la objeción de conciencia, y los jueces deben esforzarse en concederla la mayor cantidad de veces posible, mientras se puedan salvar los verdaderos derechos de las personas ${ }^{11}$.

Lo religioso comprende un amplio abanico de cosas, y no puede reducirse a la libertad de pensamiento o de conciencia: además de las creencias, existe un régimen disciplinario y cultual en cada religión, además de otros elementos relacionados como templos, objetos sagrados, hospitales, escuelas, instituciones asistenciales promovidas bajo una perspectiva religiosa. Ninguna cultura es naturalmente atea. La religión suele ser bien valorada, ya que es un valor cultural y jurídico en casi todos los sistemas del mundo. Hoy se valora especialmente la libertad religiosa ${ }^{12}$, y el derecho

\footnotetext{
${ }^{10}$ Cfr. Pacto Internacional de Derechos Civiles y Políticos (1966), art. 18.4 y la Declaración sobre la eliminación de todas las formas de intolerancia y discriminación fundadas en la religión o las convicciones (1981), art. 5.1.

${ }^{11}$ El tema del alcance y límites de la objeción de conciencia es complicado. En general, para concederla deben sopesarse varios elementos: la naturaleza de la exigencia de la autoridad, lo que se exige, la norma moral que supuestamente infringe, la postura del objetor y las circunstancias concretas. Cada uno de estos elementos contiene muchos detalles a analizar. Cfr. MARTíN DE AGAR, 1995, pp. 519543; MARTÍNEZ-TORRÓN, 1989, p. 150; NAVARRO VALLS y PALOMINO, 1994, p. 1095 y ss.

12 Bien lo expresa la célebre Declaración de Derechos de Virginia de 1776: "que la religión, o el deber
} 
estadounidense incluso ha declarado que la facultad de adherir, tener, dejar o cambiar de religión es un derecho absoluto que no puede ser derogado, ni restringido o menoscabado de ninguna manera (Cfr. WITTE, 2019, pp. 105). En cambio, no se admiten conductas que lesionen los derechos de terceros, ni aunque fueran hechas con ánimo religioso.

El gobierno de Israel deja a cada religión la posibilidad de regular muchas cuestiones relacionadas con lo religioso, como la forma de contraer matrimonio, su duración, la regulación del vínculo conyugal, la vida familiar, además de otras cuestiones que más obviamente le pertenece regular a cada comunidad (como el culto, la disciplina religiosa y la organización de cada comunidad religiosa). De alguna manera, se trata de un anarquismo religioso, donde cada comunidad religiosa puede autodeterminarse jurídicamente, y donde cada persona puede optar por el régimen jurídico-religioso que más se ajuste a sus íntimas convicciones. Y esto nos parece muy loable, una meta a buscar, una batalla que vale mucho la pena luchar.

\section{IV.4. Propiedad, mercado y empresa}

En este tema existe un choque de posturas anarquistas: las anarco-comunistas y el anarquismo del mercado libre (free-market anarchism). La primera postura, donde podemos enmarcar Peter Kropotkin, defiende la abolición del estado, del mercado, del dinero, de la propiedad privada y del capitalismo, en favor de la propiedad común de los medios de producción. En la segunda postura autores Kevin Carson (2008), Gary Chartier (2012) y Samuel Edward Konkin (1983), mantienen la idea de la propiedad privada, del dinero y del mercado, pero excluyen la figura del control estatal: el sistema económico debe basarse en la libre voluntad de sus agentes, sin intervención estatal.

Desde la caída del muro de Berlín y de la Unión de Repúblicas Socialistas Soviéticas (URSS), el comunismo anda de capa caída y se percibe muchas veces como un aparataje poco funcional, incapaz de realizar las aspiraciones humanas. Tampoco se lo suele ver con buenos ojos al capitalismo liberal extremo, donde el Estado está atado de manos para intervenir en el mercado. Prácticamente todos los países han decantado en una especie de economía social de mercado, donde hay amplios espacios de libertad y a la vez una regulación, que día a día crece en número

que tenemos para nuestro Creador y el modo en que lo reconocemos, han de guiarse por la razón y la convicción, y no por la fuerza o la violencia; y por ello, todos los hombres tienen igual derecho al libre ejercicio de la religión, de acuerdo con los dictados de su conciencia (...)" (punto XVI). 
de normas y en incidencia.

Nos parece que la solución aquí es aplicar con todas sus consecuencias el principio de subsidiariedad, del que hablaremos más adelante.

\section{IV.5. Otros campos}

Existen otros campos en donde diferentes géneros de anarquismo se han propugnado: por ejemplo, el movimiento anti-globalización que ataca las estructuras y autoridades globales, el anarco-transhumanismo que lucha por una liberalización ética, política y jurídica en la experimentación con el ser humano; la anarquía cristiana que huye de las estructuras jerárquicas eclesiales en términos pacifistas generalmente, los anarco-sindicalistas que buscan abolir la autoridad del empresario. Dentro de la Unión Soviética, también hubo anarquistas que deseaban eliminar el Estado represor que veían delante sus ojos. Los movimientos feministas también tuvieron su brazo anárquico, así como el del free love de los años 60. En general, lo que buscaba cada uno de estos anarquismos, más que ofrecer una propuesta completa de forma de gobierno, era minar la legitimación de la autoridad y de la ley del momento (fuera está a favor de capitalismo o del comunismo, de la ética o del derecho, de la regulación vigente en materia sexual o de mujeres, etc.). Y quizás el punto de acuerdo entre estos movimientos es simplemente "que cada quien haga lo que quiera", aunque ni esto es tan absoluto, porque muchos anarquistas no son individualistas, sino que funcionan de modo corporativista o asociacionista, con asambleas que toman decisiones vinculantes para todo el grupo.

En cada uno de los campos mencionados probablemente haya un área donde sea conveniente un cierto grado de anarquismo. Es claro, por ejemplo, que en las relaciones internacionales la comunidad de naciones no puede intervenir dentro de la política interna de los países, a menos que existan motivos graves que lo justifiquen (por ejemplo, razones de ayuda humanitaria). Para muchos imperios y Estados antiguos de todos los tiempos, el tema de la orientación sexual ha sido llevado descuidadamente; solo regulaban el matrimonio, entendido en términos tradicionales, porque el nacimiento de nuevos ciudadanos dependía de ello. ¿Cómo determinamos cuándo el Estado es incompetente y su intervención es perjudicial? Intentaremos responder esto en el próximo capítulo. 


\section{ALGUNOS CRITERIOS PARA FOCALIZAR EL ANARQUISMO}

Consideramos que pueden existir, al menos, tres criterios para justificar la anarquía en algún punto concreto: (i) la incapacidad fáctica del Estado para regular y controlar ciertas áreas, por tener recursos escasos para hacerlo, por no contar con el personal adecuado, por una guerra o calamidad que le impida dedicar energías a otras cuestiones menos urgentes, o por cualquier otra circunstancia; (ii) porque el Estado es jurídicamente incompetente para regular y controlar esa área; y, (iii) porque, aunque fuera competente, es políticamente inconveniente esa intromisión en lo privado. Este último criterio avanza bajo un razonamiento político que analiza los pros y los contras de cada política pública, y — siempre y cuando se enmarque en la leypermite una amplia gama de opciones a la autoridad, que bien puede decidirse por una fuerte intervención, una intervención media, leve o ninguna. Hablaremos a continuación más del criterio jurídico de incompetencia, que se mueve más bajo los parámetros de necesidad, que de conveniencia.

En derecho se ha desarrollado el principio de subsidiariedad, que sobre todo es un principio de incompetencia ${ }^{13}$. Este principio fundamentalmente señala que las sociedades mayores son incompetentes para inmiscuirse en el ámbito de las sociedades menores, y de los individuos, cuando estos últimos pueden adecuadamente alcanzar sus propios fines. Así, el Estado, ni los sindicatos pueden controlar las funciones propias de los padres (v.gr. manutención y educación de los hijos), cuando ellos pueden suficientemente cumplirlas. Casi en términos de un anarquismo focalizado Messner ha señalado lo siguiente:

El principio de subsidiariedad reduce las funciones del Estado a la perspectiva de su función esencial de servir al bien común. Esta se caracteriza por el hecho de que la comunidad estatal es una unidad de personas individuales y sociales que poseen sus propios fines existenciales y sus propias funciones, así como sus propios derechos y facultades, y que tan sólo pueden conseguir la plenitud esencial de su ser respondiendo a las responsabilidades derivadas de estos fines. El Estado es la comunidad al servicio de la coordinación de estas facultades y funciones en bien de todos. Por consiguiente, no cuenta con funciones y derechos, sino en cuanto las propias facultades y la propia voluntad de las personas individuales y de las pequeñas comunidades no

\footnotetext{
${ }^{13}$ El gran formulador de este principio ha sido el Magisterio Pontificio, quien desde 1891 ya indicaba que "es injusto que el individuo y la familia sean absorbidos por el Estado. Lo justo es dejar a cada uno la facultad de obrar con libertad hasta donde sea posible, sin daño del bien común y sin injuria de nadie" (encíclica Rerum Novarum, $\mathrm{n}^{\circ} 26$ ). En posteriores encíclicas desarrollará con más precisión este principio. Sobre su historia y contenido, véase nuestro estudio "Evolución, alcance y límites del principio de subsidiariedad". En Rubén Méndez Reátegui (ed.), Derecho y Economía. Estudios institucionales, IEAED, Quito 2019, pp. 331-353.
} 
puedan satisfacer sus propios fines existenciales (MESSNER, 1967, pp. 949950; las cursivas son nuestras).

Lo más interesante de este principio es su "valor universal". "Tiene igual valor cuando se trata de sociedades o agrupaciones menores y de orden inferior respecto de las mayores y más elevadas" (PÍO XII, 1946). Es decir, la subsidiariedad aplica tanto al Estado, como a los grandes colectivos, como a las asociaciones, sindicatos, empresas y otras agrupaciones, frente a otras entidades menores, como lo son la familia y el individuo. A la vez, esta directriz también aplica a las diversas comunidades de naciones, que en general se declaran incompetentes para meterse en los asuntos de los Estados cuando ellos puedan resolver sus problemas ${ }^{14}$.

En otro estudio específico sobre el tema (RIOFRIO, 2019), hemos dicho que el principio fuerte de subsidiariedad -aquel que declara la incompetencia de intervención de la sociedad mayor- opera en la medida en que se cumplan cinco requisitos: (i) Que existan dos sujetos realmente distintos, con autonomía propia; (ii) que un sujeto sea superior a otro según algún tipo de potestad jurídica, pública o privada; (iii) que el inferior sea anterior al superior; (iv) que el sujeto inferior tenga unas competencias y fines propios anteriores; $y,(v)$ que el sujeto inferior pueda alcanzar de una manera adecuada sus fines y cumplir sus cometidos con sus propios esfuerzos y recursos. La aplicación de este principio jurídico es bastante técnica, por lo tanto, debemos referirnos al estudio antes mencionado.

En cualquier caso, consideramos que estos criterios nos ayudan a definir con una relativa claridad que áreas, temas o ámbitos deben estar excluidos de la intervención estatal (y de la intervención de las corporaciones, sindicatos o sociedades mayores). Aplicando este principio creemos que es obvio que el Estado es incompetente de inmiscuirse en los temas de familia, derecho de los padres, educación, conciencia, moral, religión, etc. que antes hemos mencionado. En ellos debería imperar una buena dosis de anarquía.

\section{CONSIDERACIONES FINALES}

Con base a lo anterior, podemos sacar las siguientes conclusiones:

1. En la historia rara vez se ha incluido al anarquismo dentro de las

\footnotetext{
${ }^{14}$ En este sentido Benedicto XVI ha destacado que "el gobierno de la globalización debe ser de tipo subsidiario" (encíclica Caritas in veritate, n. 57).
} 
clasificaciones de formas de gobierno.

2. Tomás de Aquino señaló que la mejor forma de gobierno era la monarquía, porque ella aportaba más paz, seguridad y unidad. Pero siguiendo el ejemplo de Dios, que gobierna a todos a través de los ángeles y de los seres humanos, consideró que la mejor forma de gobierno debe ser una fórmula mixta: en parte reino, en parte oligarquía (entendida como el gobierno de los virtuosos) y en parte democracia. Hoy en día nuestros Estados han alcanzado un sistema similar, donde la figura presidencial se asimila a la monarquía, el gabinete y los ministros se asimilan a la oligarquía y la legislatura a la democracia. Sería necesario integrar la anarquía en este sistema mixto.

3. Hemos visto que una anarquía absoluta (donde no existe ningún tipo de autoridad) es simplemente inviable en las grandes sociedades. Tal vez sea posible en comunidades pequeñas. Las comunidades medianas necesitan una cierta estructura, autoridades y normas (sindicatos, consejos, asambleas, etc.).

4. Por otro lado, en las grandes comunidades la anarquía es problemática. Hay ciertas áreas donde un régimen anárquico se vuelve caótico, o simplemente no puede operar. Por ejemplo, las carreteras interprovinciales y las grandes obras públicas, las organizaciones de milicias para defender un país y la protección contra las violaciones de los derechos no pueden manejarse dentro de un sistema anarquista absoluto. En estos asuntos, el anarquismo funciona mal o, simplemente, no funciona.

5. Al mismo tiempo, hoy parecería muy aconsejable extender el anarquismo a ciertos campos de la vida social relacionados con la familia y los derechos de los padres, con la educación de los menores bajo la tutela de los padres, así como con ciertas cuestiones de conciencia, moral y religión. En otras áreas como el mercado, el derecho de propiedad y el derecho corporativo también sería deseable aumentar el nivel de autogobierno.

6. Existen tres razones que justifican la anarquía: la imposibilidad objetiva de control estatal, la incompetencia legal para llevar a cabo una intervención jurisdiccional y que tal intervención no sea políticamente conveniente. Esta última razón no es apodíctica, pues el derecho admite muchos grados de intervención de las autoridades.

7. El principal criterio para definir si el Estado (junto a los sindicatos, corporaciones, empresas, sociedades mayores, etc.) es incompetente para inmiscuirse en la vida de los individuos es el principio de subsidiariedad. Este principio fundamentalmente señala que las sociedades mayores son incompetentes para 
inmiscuirse en el ámbito de las sociedades menores, y de los individuos, cuando estos últimos pueden adecuadamente alcanzar sus propios fines. Este principio nos ayuda a determinar en qué campos se exige una anarquía focalizada y en qué áreas la anarquía se vuelve inviable.

\section{REFERÊNCIAS BIBLIOGRÁFICAS}

ARISTÓTELES. Politics. (B. Jowett, Trans.) Kitchener, Canada: Batoche Books. 1999.

Disponible

en: <https://web.archive.org/web/20130722201525/http://socserv2.mcmaster.ca/ econ/u gcm/3l|3/aristotle/Politics.pdf> Accedido el: 02 feb. 2020.

ARMAND, Émile. La révolution sexuelle et la camaraderie amoureuse. Paris: Paris Zones. 1929.

BAKUNIN, Mikhail. Natural Law and Authority. Escrito en 1871. Publicado en The Voluntaryist, Junio 1992.

BAKUNIN, Mikhail. Statism and Anarchy. (M. Shatz, Trans.) Cambridge, England: Cambridge University Press. 1990.

BENEDICTO XVI. Encíclica Caritas in veritate. 2009. Disponible en: $<$ http://www.vatican.va/content/benedict-xvi/en/encyclicals/documents/hf_benxvi_enc_20090629_caritas-in-veritate.html> Accedido el: 02 feb. 2020.

CAPPELLETTI, Ángel. La ideología anarquista. Barcelona: El Grillo Libertario. 2010.

CARSON, Kevin. Organization Theory: A Libertarian Perspective. Charleston, South Carolina: BookSurge. 2008.

CHARTIER, Gary. Anarchy and Legal Order: Law and Politics for a Stateless Society. Cambridge, England: Cambridge University Press. 2012.

CLEYRE, Voltairine de. Anarchism. New York: Free Society. 1901.

ESCOBEDO CETINA, Humberto. Ricardo Flores Magón: semblanza biográfica. Oaxaca, Mexico: Carteles Editores. 2000.

FERRER GUARDIA, Francesc. La escuela moderna. España. 1908.

GELDERLOOS, Peter. Anarchy Works: Examples of Anarchist Ideas in Practice. San Francisco, United States: Ardent Press. 2010

GLIOTI, Andrea. Rojava: A libertarian myth under scrutiny. Al Jazeera. 5 of August de 2016. Disponible en: <https://www.aljazeera.com/indepth/opinion/2016/08/rojavalibertarian-myth-scrutiny-160804083743648.html> Accedido el: 02 feb. 2020. 
GODWIN, William. Enquiry Concerning Political Justice and its Influence on Morals and Happiness. London, England: G.G.J. and J. Robinson. 1793.

GOLDMAN, Emma. Anarchism and Other Essays. New York: Mother Earth Publishing. 1910.

GÓMEZ-MÜLLER, Alfredo. Anarquismo: Lo político y la antipolítica. Bogotá, D.C.: Ediciones desde abajo. 2014.

HART, Hebert. L.A. The Concept of Law. 2d ed. Oxford: Oxford University Press. 1998.

HERODOTO. The Histories. (G. Rawlinson, Trans.) Idaho, United States of America: Roman Roads Media. 2013. Disponible en: $<$ https://files.romanroadsstatic.com/materials/herodotus.pdf> Accedido el: 02 feb. 2020.

HERVADA, Javier. Una caro. Pamplona: Eunsa. 2000.

HOBBES, Thomas. De Cive. Paris. 1642.

HOBBES, Thomas. Leviatán. 2nd ed . (A. Escohotado, Trans.) Madrid: Editora Nacional. 1980.

JUAN PABLO II. Carta a las familias. Vaticano: Editrice Vaticana. 2-II-1994.

KONKIN, Samuel Edward. New Libertarian Manifesto. 2nd ed. Durham: Koman Publishing Co. 1983.

KROPOTKIN, Pierre. La Conquête du Pain. Paris: Tresse a stock. 1892.

LEÓN XIII. Rerum Novarum. [Encyclical letter]. 1891. Disponible en: <http://www.vatican.va/content/leo-xiii/en/encyclicals/documents/hf_I-

xiii_enc_15051891_rerum-novarum.html> Accedido el: 02 feb. 2020.

LOEWENSTEIN, Karl. Verfassungslehre. 2nd ed. Tübingen: Mohr Siebeck. 1969.

MAQUIAVELO, Nicolás. The Prince. (H. Mansfield, Trans.) Chicago, United States of America: The University of Chicago Press. 1998. Disponible en: <https://monoskop.org/images/1/14/Machiavelli_Niccolo_The_Prince_1985.pdf> Accedido el: 02 feb. 2020.

MACKAY, John Henry. Die Anarchisten. (K. Henckell, Ed.) Switzerland. 1891.

MARTíN DE AGAR, José Tomás. Problemas jurídicos de la objeción de conciencia. Scripta Theologica, 1995, 27(2), pp. 519-543.

MARTÍNEZ-TORRÓN, Javier. Las objeciones de conciencia en el derecho internacional y comparado. Estudios de derecho judicial. 2006, 89, pp. 99-148. 
MESSNER, Jhoannes. Etica social, política y económica a la luz del derecho natural. (J. L. Barrios Sevilla, Trans.) Madrid: Ediciones Rialp. 1967.

NAVARRO-VALLS, Rafael y PALOMINO, Rafael. Las objeciones de conciencia: conflictos entre conciencia y ley en el derecho norteamericano. Madrid: Red de Bibliotecas Universitarias. 1994.

NOZICK, Robert. Anarchy, state, and utopia. Oxford: Basil Blackwell. 1974

ONFRAY, Michel. Théorie du corps amoureux : pour une érotique solaire. Paris: Le Club. 2000.

PíO XII. La elevatezza. Acta Apostolicae Sedis. 1946. XIII(II), 141-151. Disponible en: <http://www.vatican.va/archive/aas/documents/AAS-38-1946-ocr.pdf> Accedido el: 02 feb. 2020.

PLATÓN. The Republic. En B. Jowett, The Dialogues of Plato,1892. 3rd ed. vol. 3. London, England: Oxford University Press. 1892. Disponible en: $<$ https://oll.libertyfund.org/titles/plato-dialogues-vol-3-republic-timaeus-critias\#If013103_head_001> Accedido el: 02 feb. 2020.

PONTIFICIO CONSEJO PARA LA FAMILIA. Carta de los Derechos de la Familia. Vaticano: Editrice Vaticana. 22 oct. 1983.

PROUDHON, Pierre-Joseph. General Idea of the Revolution in the Nineteenth Century. (J. B. Robinson, Trans.) Lodndres: Freedom Press. 1923.

RIOFRIO, Juan Carlos. Evolución, alcance y límites del principio de subsidiariedad. En Rubén Méndez Reátegui (ed.), Derecho y Economía. Estudios institucionales. Quito: PUCE, 331-353. 2019.

ROUSSEAU, Jean-Jacques. El Contrato Social o Principios del Derecho Político. 1762. (L. Halperín, Trans.) Buenos Aires-Argentina: Editorial Losada S.A. 2003.

STIRNER, Max. Der Einzige und sein Eigentum. O. Wigand (ed.) Leipzig, 1844.

TOMAS DE AQUINO. Suma Teológica. París-Italia, 1265-1272. Traducción de AA.VV. (BAC). Suma Teológica de Santo Tomás de Aquino, 4를 ed. Madrid: BAC, 2001.

TOMÁS DE AQUINO. On Kingship: To the King of Cyprus. (Trad. de G. B. Phelan) Toronto, Canada: Aeterna Press, 2015.

VERDUGO, Mario. Funciones de las Fuerzas Armadas y el Consejo de Seguridad Nacional en Chile de acuerdo a las propuestas de la Reforma Constitucional. lus et Praxis, 2002. 8(1), 53-70.

VIRGINIA, Declaración de derechos. Fifth Virginia Convention. Williamsburg, Virginia, 12 jun. 1776.

WARREN, Josiah. Manifesto. New Jersey: Oriole Press. 1952. 
WITTE Jr. John. La libertad religiosa en Estados Unidos: Una perspectiva internacional. Revista de Derecho lus Humani, 8, 2019, pp. 105 y ss.

WOODCOCK, George. The Anarchist Reader. Great Britain: Fontana Paperbacks. 1977.

Recebido em 03/03/2020

Aprovado em 20/04/2020

Received in 03/03/2020

Approved in 20/04/2020 